\title{
Carbon Monoxide Abrogates Ischemic Insult to Neuronal Cells via the Soluble Guanylate Cyclase-cGMP Pathway
}

\author{
Nils Schallner ${ }^{1 *}$, Carlos C. Romão ${ }^{2,5}$, Julia Biermann ${ }^{3}$, Wolf A. Lagrèze ${ }^{3}$, Leo E. Otterbein ${ }^{4}$, \\ Hartmut Buerkle ${ }^{1}$, Torsten Loop ${ }^{1}$, Ulrich Goebel ${ }^{1}$
}

1 Department of Anesthesiology, Division for Experimental Anesthesiology, University Medical Center Freiburg, Germany, 2 Instituto de Tecnologia Química e Biológica, Universidade Nova de Lisboa, Oeiras, Portugal, 3 University Eye Hospital, University Medical Center Freiburg, Germany, 4 Beth Israel Deaconess Medical Center, Department of Surgery, Harvard Medical School, Boston, Massachusetts, United States of America, 5 Alfama Limitida, Instituto de Biologia Experimental e Tecnológica, Oeiras, Portugal

\begin{abstract}
Purpose: Carbon monoxide (CO) is an accepted cytoprotective molecule. The extent and mechanisms of protection in neuronal systems have not been well studied. We hypothesized that delivery of CO via a novel releasing molecule (CORM) would impart neuroprotection in vivo against ischemia-reperfusion injury (IRI)-induced apoptosis of retinal ganglion cells (RGC) and in vitro of neuronal SH-SY5Y-cells via activation of soluble guanylate-cyclase (sGC).

Methods: To mimic ischemic respiratory arrest, SH-SY5Y-cells were incubated with rotenone $(100 \mathrm{nmol} / \mathrm{L}, 4 \mathrm{~h}) \pm \mathrm{CORM}$ ALF186 (10-100 $\mu \mathrm{mol} / \mathrm{L})$ or inactivated ALF186 lacking the potential of releasing CO. Apoptosis and reactive oxygen species (ROS) production were analyzed using flow-cytometry (Annexin V, mitochondrial membrane potential, CM- $\mathrm{H}_{2} \mathrm{DCFDA}$ ) and Western blot (Caspase-3). The impact of ALF186 \pm respiratory arrest on cell signaling was assessed by measuring expression of nitric oxide synthase (NOS) and soluble guanylate-cyclase (sGC) and by analyzing cellular cGMP levels. The effect of ALF186 (10 mg/kg iv) on retinal IRI in Sprague-Dawley rats was assessed by measuring densities of fluorogold-labeled RGC after IRI and by analysis of apoptosis-related genes in retinal tissue.

Results: ALF186 but not inactivated ALF186 inhibited rotenone-induced apoptosis (Annexin $V$ positive cells: $25 \pm 2 \%$ rotenone vs. $14 \pm 1 \%$ ALF186+rotenone, $\mathrm{p}<0.001$; relative mitochondrial membrane potential: $17 \pm 4 \%$ rotenone vs. $55 \pm 3 \%$ ALF186+rotenone, $p<0.05)$. ALF186 increased cellular cGMP levels $(33 \pm 5 \mathrm{nmol} / \mathrm{L}$ vs. $23 \pm 3 \mathrm{nmol} / \mathrm{L} ; \mathrm{p}<0.05)$ and $\mathrm{sGC}$ expression. SGC-inhibition attenuated ALF186-mediated protection (relative mitochondrial membrane potential: $55 \pm 3 \%$ ALF186+rotenone vs. $20 \pm 1 \%$ ODQ+ALF186+rotenone, $\mathrm{p}<0.05)$. ALF186 protected RGC in vivo (IRI $1255 \pm 327 \mathrm{RGC} / \mathrm{mm}^{2} \mathrm{vs}$. ALF186+IRI 2036 $\pm 83 ; p<0.05$ ) while sGC inhibition abolished the protective effects of ALF186 (ALF186+IRI 2036 \pm 83 RGC/ $\mathrm{mm}^{2}$ vs. NS-2028+ALF186+IRI 1263 $\left.\pm 170, \mathrm{p}<0.05\right)$.
\end{abstract}

Conclusions: The CORM ALF186 inhibits IRI-induced neuronal cell death via activation of sGC and may be a useful treatment option for acute ischemic insults to the retina and the brain.

Citation: Schallner N, Romão CC, Biermann J, Lagrèze WA, Otterbein LE, et al. (2013) Carbon Monoxide Abrogates Ischemic Insult to Neuronal Cells via the Soluble Guanylate Cyclase-cGMP Pathway. PLoS ONE 8(4): e60672. doi:10.1371/journal.pone.0060672

Editor: Karl-Wilhelm Koch, University of Oldenburg, Germany

Received December 12, 2012; Accepted March 1, 2013; Published April 8, 2013

Copyright: (c) 2013 Schallner et al. This is an open-access article distributed under the terms of the Creative Commons Attribution License, which permits unrestricted use, distribution, and reproduction in any medium, provided the original author and source are credited.

Funding: This work was funded by departmental funding of the Department of Anesthesiology and Critical Care Medicine and the University Eye Hospital, University Medical Center Freiburg, Germany. The funders had no role in study design, data collection and analysis, decision to publish, or preparation of the manuscript.

Competing Interests: The authors have read the journal's policy and have the following conflicts: Author Carlos C. Romão is a co-founder, administrator and scientific officer of the company Alfama Lda. where he has equity interests. CC Romão is an inventor in Patent-No.: US 2011/0038955 A1 2011 where ALF186 exemplifies the protection of the stomach against NSAID generated ulcers by the administration of CORMs, and is therefore irrelevant for the matter of the present article. The drug profile of ALF186 is published in detail in: Anästhesiologische Universitätsklinik Prof. Karl-Wilhelm Koch, PhD Academic Editor Public Library of Science - PLOS ONE Dr. med. Nils Schallner Hugstetter Str. 55 D 79106 Freiburg GERMANY Tel +49-761-270-23060 Fax +49-761-270-23960 E-Mail nils. schallner@uniklinik-freiburg.de Freiburg, February 25, 2013 University Medical Center Freiburg Department of Anesthesia and Critical Care Medicine • D 79106 Freiburg Cover Letter Dalton Transactions DOI: 10.1039/c2dt32174b. Author Leo E. Otterbein as a former collaborator of Alfama Lda. no longer has any professional relationship or equity interests in the company. These conflicts of interest do not alter the authors' adherence to all the PLOS ONE policies on sharing data and materials. The remaining authors declare no competing financial interests.

*E-mail: nils.schallner@uniklinik-freiburg.de

\section{Introduction}

Ischemic injury to neuronal cells might occur in the perioperative period during major cardiovascular but also non-cardiac surgical procedures [1]. Against current dogma that carbon monoxide $(\mathrm{CO})$ is poisonous, particularly to the brain, emerging data suggest that at low doses $\mathrm{CO}$ provides potent neuroprotection by its anti-inflammatory and anti-apoptotic properties [2,3]. The application of $\mathrm{CO}$ releasing molecules (CORMs) may be a valuable alternative to inhaled $\mathrm{CO}$, because they can be administered to biological systems via systemic routes and potentially in a tissuespecific manner thus avoiding unreliable inhaled application and allowing safe administration to target organs such as the central nervous system. CORMs suppress the inflammatory response in 
glial cells in vitro [4] and might therefore exhibit neuroprotection. However, other findings have elicited some confusion as to the consistency of the neuroprotective effects, which may reflect the choice of CORM. The well-described ruthenium based, watersoluble CORM-3 is effective when given before or late after neuronal injury but not when given early afterwards [5]. Here, we present data that a molybdenum-based, water-soluble CORM (ALF186) possesses a different $\mathrm{CO}$ release profile releasing $\mathrm{CO}$ in a dose- and oxygen-dependent manner after administration [6]. ALF186 has shown protective effects in vivo in models of acute inflammation [7,8] and in the regulation of vasomotor tone [9].

Given the anti-inflammatory and vascular effects of $\mathrm{CO}$ and ALF186 we hypothesized that ALF186 would be an ideal modality to assess the potential neuroprotective properties of ALF186 in vitro and in vivo in models of ischemic injury. The mechanisms of CORM-mediated protective effects have not been well studied in neuronal systems. This is of particular importance considering the large amount of data that $\mathrm{CO}$ may be neurotoxic. Hemecontaining proteins are well-described cellular targets given the affinity of $\mathrm{CO}$ for ferrous iron in heme. Binding of $\mathrm{CO}$ to heme can alter enzymatic function both positively or negatively and include soluble guanylate-cyclase (sGG), nitric oxide synthase (NOS) and NADPH oxidase as well as the mitochondrial cytochrome c oxidase complexes [10]. The role of these "primary targets" in mediating anti-inflammatory [11], anti-proliferative [12] and vasoactive [13] effects of CORMs have been characterized in non-neuronal systems, but not in neuronal systems. Indirect effects of $\mathrm{CO}$ on non-heme proteins have also been shown to contribute to its protective effects [10].

$\mathrm{CO}$ has emerged as a gaseous neurotransmitter that modulates neuronal cGMP levels [14]. CO and CORMs are known sGCactivators, leading to a moderate increase in cGMP production $[9,13,15]$. Growing evidence supports a role for the sGC-cGMP pathway in CO-mediated protection of neuronal cells against apoptosis $[2,16]$. However, little is known whether CORMmediated neuroprotective effects occur through this pathway. Protective effects that occur through activation of sGC-cGMP signal transduction seem to be mediated through protein kinase G1 (PKG1) activation [16] albeit the distinct cellular downstream targets for these protective effects remain unknown.

\section{Materials and Methods}

\section{Reagents}

The carbon monoxide releasing molecule ALF186 ([Mo(CO) $)_{3}(-$ histidinato)]Na; Fig. 1; Alfama Inc., Lisbon, Portugal) was kindly provided by C. Romão [6,8]. It was freshly dissolved in PBS prior to cell culture treatment. The inactive compound iALF186 was prepared by dissolving ALF186 in PBS and incubated for $24 \mathrm{~h}$ under exposure to air and light. After $24 \mathrm{~h}$, the solution was bubbled with nitrogen to remove residual carbon monoxide.

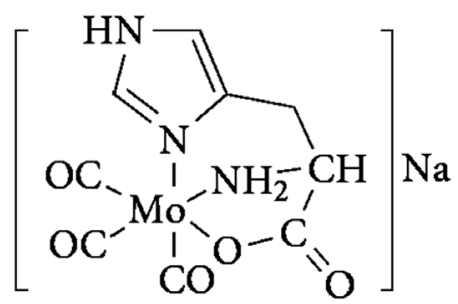

Figure 1. Chemical structure of ALF186. Carbon monoxide liberating compound containing a central molybdenum atom. doi:10.1371/journal.pone.0060672.g001
Rotenone was purchased from Sigma Aldrich (Taufkirchen, Germany). It was freshly prepared by dissolving in dimethylsulfoxide (DMSO) prior to the experiments. DMSO concentration in cell culture media did not exceed $0.5 \%$.

The inhibitors of proteinkinase G-1(PKGl; KT5832), the inhibitor (ODQ) and the inductor (YC-1) of the soluble guanylate-cyclase (sGC) and the cGMP-analogue 8-Br-cGMP were obtained from Sigma Aldrich, as were the inhibitors of the nitric oxide synthase (NOS) L-NAME and of the NADPH oxidase DPI (diphenylene iodonium).

\section{Cell Culture and Treatment}

Neuroblastoma cells (cell line SH-SY5Y; ATCG No. CRL2266) were cultured in DMEM medium (with penicillin/streptomycin, $1 \%$ glutamate and $10 \%$ fetal bovine serum) in a humidified atmosphere with $5 \%$ carbon dioxide at $37^{\circ} \mathrm{C}$ constant temperature until $80 \%$ confluence was achieved. The cells were usually seeded in 6 well culture plates at a density of approximately $3 \times 10^{5}$ per well $24 \mathrm{~h}$ prior to individual treatment. Before rotenone treatment, the cells were transferred into media containing $0.5 \%$ fetal bovine serum, to prevent inactivation of rotenone by protein binding. Cells were pre-treated with $10-100 \mu \mathrm{mol} / \mathrm{L}$ ALF186 or iALF186 $30 \mathrm{~min}$ before induction of apoptosis with $100 \mathrm{nM}$ Rotenone. After $4 \mathrm{~h}$ of rotenone-treatment, cells were collected for quantification of apoptosis or protein and gene expression analysis. For assays analyzing the influence of ALF186 alone without rotenone-treatment, cells were collected $1 \mathrm{~h}$ after ALF186 treatment.

\section{Quantification of Apoptosis}

Staining with Annexin V-FITC and propidiumiodide (Becton Dickinson, Heidelberg, Germany) and flow-cytometric analyses were done as previously described [17]. Western Blots were done as previously described [17] using antibodies against cleaved Caspase-3 (\#9664 from Cell Signaling Technology, Danvers, MA, USA) and GAPDH (\#CSA-335 from Enzo Lifesciences, Plymouth, PA, USA).

\section{Quantification of Mitochondrial Membrane Potential Loss}

Mitochondrial membrane potential $\left(\Delta \Psi_{\mathrm{m}}\right)$ was quantified using the Mito-Probe JC-1 Assay (Molecular Probes, Invitrogen, Darmstadt, Germany). SH-SY5Y cells were stained with $2 \mu \mathrm{mol} / \mathrm{L}$ JC-1 for $15 \mathrm{~min}$ prior to cell collection after treatment with rotenone, ALF186 or inhibitors as indicated in the individual experiments. Cells were analyzed using flow-cytometry. JC-1 exhibits mitochondrial membrane potential-dependent accumulation in mitochondria, which leads to formation of aggregates and a fluorescence emission shift from green to red. As a consequence, mitochondrial depolarization is indicated by a decrease in the ratio of red/green fluorescence intensity. The ratio between red and green fluorescence intensity was calculated. While the ratio in untreated cells was set to $100 \%$, the difference compared to treated cells was used to describe a loss in mitochondrial membrane potential.

\section{Analysis of Primary Carbon Monoxide Targets}

Soluble guanylate cyclase (sGG) and corresponding cGMP were analyzed using a cGMP detection kit (Cell Signaling Technology, Danvers, MA, USA). Expression of the sGC $\alpha$ and $\beta_{1}$ subunits were quantified using RT-PCR, while the subunit proteins were visualized with Western blot analyses (sGC $\alpha_{1}$ : \#160895; sGC $\beta_{1}$ : \#160897 from Cayman Chemical, Ann Arbor, MI, USA). Selective induction of sGC was achieved using YC-1 and selective 
inhibition via ODQ using $20 \mu \mathrm{mol} / \mathrm{L}$ for $30 \mathrm{~min}$ and $10 \mu \mathrm{mol} / \mathrm{L}$ for $30 \mathrm{~min}$ respectively. Also, a cell permeable cGMP-analogue (8Br-cGMP, $1 \mathrm{mmol} / \mathrm{L}, 30 \mathrm{~min}$ ) was used to mimic sGC activation. Protein kinase G-1 (PKG1, cGK1) as a downstream target of cGMP was inhibited with the selective inhibitor KT5823 (1 $\mu \mathrm{mol} /$ $\mathrm{L}, 1 \mathrm{~h}$ ). Expression of the inducible (i) and neuronal (n) isoforms of nitric oxide synthase (NOS) was analyzed using Western blot (iNOS: \#2977; nNOS: \#4236 from Cell Signaling Technology, Danvers, MA, USA). Inhibition of NOS was achieved by incubation with L-NAME $(50 \mu \mathrm{mol} / \mathrm{L}, 30 \mathrm{~min})$ and inhibition of NADPH oxidase was performed using diphenylene iodonium (DPI, $10 \mu \mathrm{mol} / \mathrm{L}, 1 \mathrm{~h}$ ).

\section{Quantification of Nitric Oxide Production}

Nitric oxide production was quantified by measurement of total nitrite concentration in cell supernatants using the Griess Method (Nitric Oxide Colorimetric Assay Kit, BioVision, Milpitas, CA, USA) following the manufacturer's instructions. Absorbance at $540 \mathrm{~nm}$ was then read on a microplate reader (Molecular Devices, SpectraMax, Biberach, Germany) to quantify total nitrite content in the samples.

\section{Reactive Oxygen Species}

Quantification of reactive oxygen species (ROS) was assessed using the fluorescence dye CM- ${ }_{2}$ DCFDA (Invitrogen, Karlsbad, Germany) by flow-cytometry. Incorporation of CM- ${ }_{2}$ DCFDA is indicative of intracellular formation of ROS and can be assessed by quantification of fluorescence intensity in FL-1. A positive control was obtained using phorbol-myristate-acetate (PMA, Sigma Aldrich, Taufkirchen, Germany) at a concentration of $1 \mu \mathrm{mol} / \mathrm{L}$ for $5 \mathrm{~min}$.

\section{Animals}

Adult male and female Sprague-Dawley rats (1:1, 280-350 g body weight, Charles River, Sulzfeld, Germany) were used. Animals were fed a standard rodent diet ad libitum while kept on a 12-h light/12-h dark cycle. All procedures involving animals concurred with the approval of The Association for Research in Vision and Ophthalmology and were approved by the Committee of Animal Care of the University of Freiburg (Permit Number: 359185.81/G-11/81). All types of surgery and manipulations were performed under general anesthesia with isoflurane $/ \mathrm{O}_{2}$ for retrograde labeling with fluorogold or a mixture of intraperitoneally administered ketamine $50 \mathrm{mg} / \mathrm{kg}$ (Ceva-Sanofi, Germany) and xylazine $2 \mathrm{mg} / \mathrm{kg}$ (Ceva-Sanofi) for the ischemia reperfusion experiments. Body temperature was maintained at $37 \pm 0.5^{\circ} \mathrm{C}$ with a heating pad controlled by a rectal thermometer probe. After surgery, buprenorphine (50 $\mu \mathrm{g} / \mathrm{kg}$; Essex Pharma, Germany) was applied subcutaneously to treat pain. While recovering from anesthesia, animals were placed in separate cages and gentamicin ointment (Refobacin ${ }^{\circledR}$; Merck, Darmstadt, Germany) was applied on ocular surfaces and skin wounds. The number of animals used for RGG quantification and molecular analysis was $n=6$ per group.

\section{Retrograde Labeling of RGC}

Rats were anesthetized with isoflurane, placed in a stereotactic apparatus (Stoelting, Kiel, Germany) and retrograde RGClabeling was done as described previously [18]: The skin overlying the skull was cut open und retracted. The lambda and bregma sutures served as landmarks for drilling 3 holes on each site of the bregma suture. A total amount of $7.8 \mu \mathrm{l}$ fluorogold (FG) (Fluorochrome, Denver, CO, USA) dissolved in 10\% dimethylsulf- oxide in PBS was injected into both lateral superior colliculi through the drilling holes. To ensure adequate retrograde transport of FG into the RGC's perikarya, further experimental interventions were done 7 days after retrograde labeling.

\section{Retinal Ischemia/Reperfusion Injury and Treatment with ALF186}

Rats were anesthetized intraperitoneally with xylazine and ketamine. To evaluate a neuroprotective effect of carbon monoxide released from ALF186, animals were randomized to receive treatment with $\mathrm{ALF} 186(10 \mathrm{mg} / \mathrm{kg}$ body weight i.v., dissolved in PBS) or PBS (vehicle controls) alone $30 \mathrm{~min}$ prior to initiation of ischemia. A third group received NS-2028 (inhibitor of sGC; Sigma Aldrich; $7 \mathrm{mg} / \mathrm{kg}$ body weight i.v. dissolved in DMSO/PBS) $30 \mathrm{~min}$ before ALF186 treatment and subsequent ischemia/reperfusion injury. Retinal ischemia/reperfusion injury was performed as described previously [3]. Briefly the anterior chamber of the left eye was cannulated with a 30-gauge needle connected to a reservoir containing $0.9 \% \mathrm{NaCl}$. Intraocular pressure was increased to $120 \mathrm{~mm} \mathrm{Hg}$ for $60 \mathrm{~min}$ and ocular ischemia was confirmed microscopically by interruption of the ocular circulation. Rats without immediate recovery of retinal perfusion at the end of the ischemic period or those with lens injuries were excluded from the investigation, since the latter prevents RGC death and promotes axonal regeneration.

\section{RGC Quantification}

Animals were killed by $\mathrm{CO}_{2}$-inhalation 7 days after ischemia. Retinal tissue was immediately harvested, placed in ice-cold Hanks balanced salt solution and further processed for whole mount preparation. Retinae were carefully placed on a nitrocellulose membrane with the ganglion cell layer (GCL) on top. After removing the vitreous body, retinae were fixed in $4 \%$ paraformaldehyde for $1 \mathrm{~h}$ and then embedded in mounting media (Vectashield; Axxora, Loerrach, Germany). The densities of FGpositive RGG were determined using a fluorescence microscope (AxioImager; Carl Zeiss, Jena, Germany) and the appropriate bandpass emission filter (FG: excitation/emission, 331/418 nm), as previously described [19]. Briefly, we photographed 3 standard rectangular areas $\left(0.200 \mathrm{~mm} \times 0.200 \mathrm{~mm}=0.04 \mathrm{~mm}^{2}\right)$ at 1,2 and $3 \mathrm{~mm}$ distal from the optic disc in the central regions of each retinal quadrant. Hence, we evaluated an area of $0.48 \mathrm{~mm}^{2}$ per retina $\left(12 \times 0.04 \mathrm{~mm}^{2}\right)$. Assuming an average retinal area of about $50 \mathrm{~mm}^{2}$ in rats [20], we evaluated about $1 \%$ of the retina. To calculate the average RGC density in cells $/ \mathrm{mm}^{2}$, we multiplied the number of analyzed cells $/ 0.04 \mathrm{~mm}^{2}$ by 25 . Secondary fluorogold stained activated microglia cells (AMC) after RGC phagocytosis were identified by morphologic criteria and excluded from calculation. All averaged data are presented as mean RGC densities $\left[\right.$ cells $\left./ \mathrm{mm}^{2}\right] \pm \mathrm{SD}$.

\section{Real Time Polymerase Chain Reaction (RT-PCR)}

For the in vivo experiments, retinal tissue was harvested $12 \mathrm{~h}$ after IRI. For the in vitro experiments with SH-SY5Y neuroblastoma cells, cells were lysed $1 \mathrm{~h}$ after ALF186 or $4 \mathrm{~h}$ after rotenone treatment. Total RNA from each retina or from $0.5 \times 10^{6} \mathrm{SH}$ SY5Y cells was extracted using a column-purification based kit (RNeasy Micro Kit ${ }^{\circledR}$, Qiagen, Hilden, Germany) according to manufacturer's instructions. Reverse transcription was performed with 25 to $250 \mathrm{ng}$ of total RNA using random primers (High Capacity cDNA Reverse Transcription Kit, Applied Biosystems, Darmstadt, Germany). RT-PCR was done with a TaqMan ${ }^{\circledR}$ probe-based detection kit (Applied Biosystems), using the following 
primers (all from Applied Biosystems; Gene of interest/Assay ID): 1. sGC $\alpha_{1}$ human/Hs01015570_ml; 2. sGC $\beta_{1}$ human/ Hs00168336_ml; 3. GAPDH human/4326317E; 4. Bax rat/ Rn02532082_gl; 5. Bcl-2 rat/Rn99999125_ml; 6. Caspase-3 rat/ Rn00563902_ml; 7. sGC $\alpha_{1}$ rat/Rn00567252_m1; 8. sGC $\beta_{1}$ rat/Rn00562775_ml; 9. GAPDH rat/4352338E.

PCR assays were then performed on a RT-PCR System (ABI Prism 7000, Applied Biosystems) with the following cycling conditions: $95^{\circ} \mathrm{C}$ for $10 \mathrm{~min}, 40$ cycles of $95^{\circ} \mathrm{C}$ for $10 \mathrm{sec}$ and $60^{\circ} \mathrm{C}$ for $1 \mathrm{~min}$. Reaction specificity was confirmed by running appropriate negative controls. Cycle threshold (CT) values for each gene of interest were normalized to the corresponding CT values for GAPDH $(\Delta \mathrm{CT})$. Relative gene expression in IR-injured retinal tissue was calculated in relation to the corresponding gene expression in the non-injured retinal tissue of each individual animal $(\Delta \Delta \mathrm{CT})$. For in vitro experiments, relative gene expression in cells treated with ALF186 and rotenone was calculated in relation to gene expression in untreated cells $(\Delta \Delta \mathrm{CT})$.

\section{Statistical Analyses}

All data with normal distribution are presented as means \pm SD. Data without normal distribution are presented as median $\pm 25^{\text {th }}$ / $75^{\text {th }}$ percentile. For in vitro studies, one-way ANOVA was used for between-group comparisons with post hoc Holm Sidak test and Kruskal Wallis one-way ANOVA on ranks with post hoc SNK-test for data with lack of normal distribution. For the in vivo studies, we wished to detect a 50\% difference in RGC densities by intervention with ALF186. Based on previously published data [3] and assuming an expected SD of $10 \%$, an a priori power analysis ( $\alpha=0.05$ with two-sided hypothesis, power $80 \%$ ) indicated that a sample size of six animals per group would be sufficient to detect such a difference. Two-way ANOVA (RGG densities: Factor $\mathrm{A}=$ ischemia with two levels: 1 . control and 2. IRI; factor $\mathrm{B}=$ intervention with three levels: 1. vehicle, 2. ALF186, 3. NS2028+ALF186) was used for between-group comparisons with post hoc Holm-Sidak test. Data were analyzed with a computerized statistical program (SigmaStat for Windows Version 3.1, Systat Software Inc., San Jose, CA, USA). $P<0.05$ was considered statistically significant.

\section{Results}

\section{ALF186 Attenuates Rotenone-induced Apoptosis}

The ability of $\mathrm{CO}$ to prevent apoptosis of non-neuronal cells has been well described and thus led us to investigate the neuroprotective properties of ALF186 on cell death. We induced apoptosis with the mitochondrial poison rotenone in SH-SY5Y neuroblastoma cells in order to mimic the changes in cellular respiration in vitro as occurs during IRI in vivo. Exposure of cells to rotenone significantly increased the percentage of Annexin $\mathrm{V}$ positive cells (Fig. 2A-2B). ALF186, but not inactivated ALF186 (iALF186) decreased the number of Annexin V positive SH-SY5Y cells (rotenone-treated $25 \pm 2 \%$ vs. ALF186 $10 \mu \mathrm{mol} / \mathrm{L}+$ rotenone $17 \pm 2 \%$, ALF $18650 \mu \mathrm{mol} / \mathrm{L}$ +rotenone $15 \pm 2 \%$, ALF $100 \mu \mathrm{mol} /$ $\mathrm{L}+$ rotenone $14 \pm 1 \%$, all $\mathrm{p}<0.001$ ) indicating that $\mathrm{CO}$ was likely mediating the neuroprotection (Fig. 2A-2B). To further corroborate the Annexin findings we measured cleavage of caspase- 3 as a marker of apoptosis. Rotenone caused the degradation of procaspase-3 and formation of caspase-3 cleavage products (Fig. 2B), which was abrogated in the presence of ALF186. Importantly, the inactive compound without CO (iALF186) had no effect on caspase-3 cleavage.

Since rotenone inhibits the mitochondrial electron transfer chain at complex I, we next analyzed the influence of ALF186 on rotenone-induced mitochondrial depolarization as an indicator of apoptosis. Rotenone induced an $87 \%$ decrease in mitochondrial membrane potential over naïve controls $(p<0.05)$, which was comparable to depolarization after treatment with cyanide $(8 \pm 4 \%$ mitochondrial membrane potential, (Fig. 2C, p<0.05). ALF186 significantly attenuated mitochondrial depolarization caused by rotenone $(17 \pm 4 \%$ in rotenone+vehicle vs. $55 \pm 3 \%$ in ALF $186+$ rotenone treated, (Fig. 2C, p<0.05). iALF186 did not prevent mitochondrial depolarization (iALF+rotenone $15 \pm 5 \%$ ).

\section{ALF186 Acts Independently of iNOS and nNOS}

To analyze the involvement of heme-containing enzymes as CO targets in mediating neuroprotection, we next investigated whether ALF186 influenced activity and expression of the NOS enzymes. ALF186 induced expression of both the inducible and neuronal (n) isoforms of NOS (Fig. 3A). ALF186 slightly increased nitric oxide production and this increase was abolished in the presence of the NOS-Inhibitor L-NAME (Fig. 3B, p <0.05). However, inhibition of NOS with L-NAME did not influence ALF186 mediated protection against rotenone $(\mathbf{F i g}$. 3C, rotenone $17 \pm 5 \%$ of mitochondrial membrane potential vs. ALF186 $50 \mu \mathrm{mol} / \mathrm{L}+$ rotenone $55 \pm 3 \%$ and vs. L-NAME+ALF186+rotenone $60 \pm 17 \%$, both $\mathrm{p}<0.05)$.

\section{ALF186 Requires Reactive Oxygen Species Originating from NADPH Oxidase in SH-SY5Y Cells for Protection}

$\mathrm{CO}$ has been shown to transiently increase ROS in macrophages by targeting the mitochondria. The effect of $\mathrm{CO}$ on ROS generation in neurons has not been tested. Given the ability of $\mathrm{CO}$ to protect cells against rotenone, we turned to NADPH oxidase as an alternative hemoprotein target given that it also generates ROS formation and regulates cell signaling. To determine whether ALF186 influences intracellular ROS production we incubated SH-SY5Y cells with the oxidant dye CM$\mathrm{H}_{2}$ DCFDA and analyzed ROS production by flow-cytometry. Incubation with ALF186 alone resulted in a significant increase in intracellular ROS production comparable to the known NADPH oxidase inducer PMA (Fig. 4A). Increases in ROS production by ALF186 or PMA were moderate compared to the strong induction of ROS by rotenone (Fig. 4A). Inhibition of NADPH oxidase with diphenylene iodonium (DPI) resulted in abolishment of ALF186 mediated protection (Fig. 4B). Interestingly, incubation with DPI alone resulted in a significant

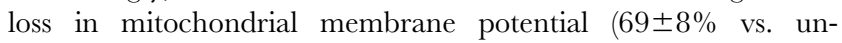
treated, $\mathrm{p}<0.05)$ suggesting either that baseline activity of NADPH oxidase in generating ROS is required for survival or that DPI has other toxic effects on mitochondria.

\section{ALF186 Induces the Activity and Expression of sGC}

To further analyze the influence of ALF186 on heme-containing potential carbon monoxide targets, we next looked at soluble guanylate-cyclase (sGC), which is known to be a key target in vascular smooth muscle [15]. ALF186, but not iALF186 significantly increased the amount of cellular cGMP, the reaction product of $\mathrm{sGC}$ from $23 \pm 3 \mathrm{nmol} / \mathrm{L}$ in control cells to $33 \pm 5 \mathrm{nmol} / \mathrm{L}$ in the presence of $100 \mu \mathrm{mol} / \mathrm{L}$ ALF 186 Fig. 5A, p < 0.05). Increases in the amount of cellular cGMP by ALF186 were effectively blocked by the sGC-Inhibitor ODQ (Fig. 5B, p < 0.05). The increase in cGMP likely reflects the ability of $\mathrm{CO}$ to influence sGC activity, however RT-PCR and Western blot analysis showed that the expression of the sGC $\beta_{1}$ subunit was also induced by ALF186 and not by iALF186 (Fig. 5C). 

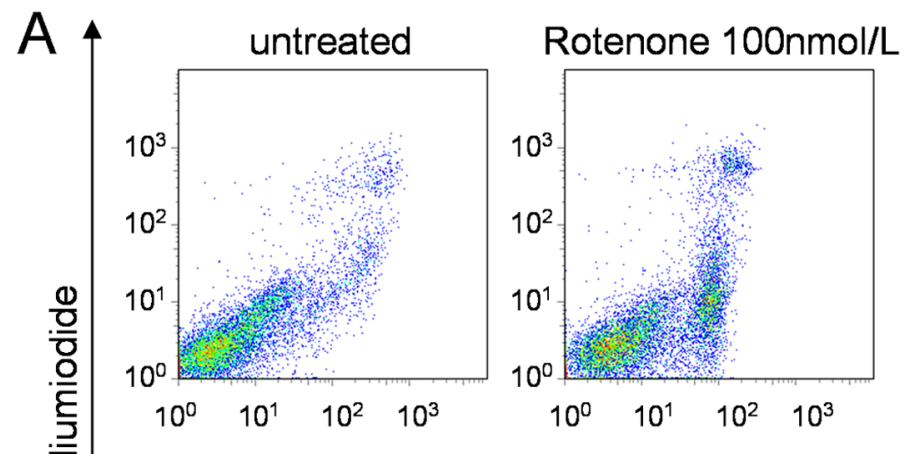

ALF186 50umol/L

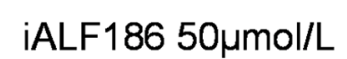
+ Rotenone
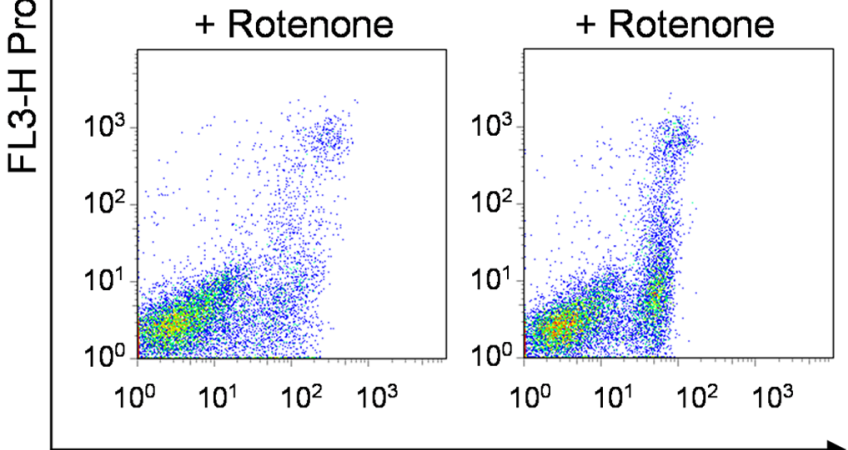

FL1-H Annexin V

B
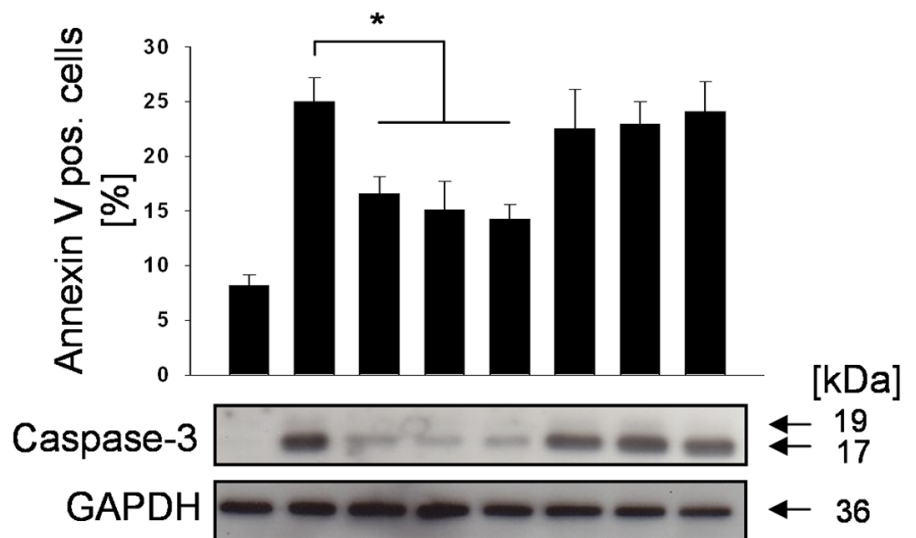

[kDa] 9

$\begin{array}{lllllllllll}\text { ALF186 } & - & - & 10 & 50 & 100 & - & - & - & \mu \mathrm{mol} / \mathrm{L} \\ \text { iALF186 } & - & - & - & - & - & 10 & 50 & 100 & \mu \mathrm{mol} / \mathrm{L} \\ \text { Rotenone } & - & + & + & + & + & + & + & + & 100 & \mathrm{nmol} / \mathrm{L}\end{array}$

igure 2. Effect of ALF186 on rotenone-induced apoptosis. A: Representative experiment after FITC Annexin $V$ and propidiumiodide staining and flow-cytometric analysis. $1 \times 10^{4}$ cells in each experiment were analyzed. B: ALF186-mediated effect on apoptosis analyzed by Annexin $V$ staining (top, $n=6 ;$ mean $\pm S D ;{ }^{*}=p<0.001$ rotenone vs. ALF186 10, 50 and $100 \mu \mathrm{mol} / \mathrm{L}+$ rotenone) and caspase-3 cleavage (bottom, representative Western blot of caspase-3 cleavage products). C: Flow-cytometric analysis of mitochondrial membrane potential change relative to untreated cells ( $\Delta \Psi_{\mathrm{m}}$, $\mathrm{n}=6 ;$ mean $\pm S D ;{ }^{*}=\mathrm{p}<0.05$ rotenone vs. ALF186+ rotenone and ALF186+ rotenone vs. iALF186+ rotenone).

doi:10.1371/journal.pone.0060672.g002

Inhibition of sGC Activation or the sGC Downstream Target PKG1 Abrogates ALF186 Mediated Protection

We next asked whether the effects of ALF186 required sGC activity. Inhibition of $\mathrm{sGC}$ activation with the selective inhibitor ODQ prior to ALF186 incubation and rotenone-treatment led to mitochondrial depolarization comparable to treatment with rotenone alone and effectively reversed the protection afforded by ALF186 (Fig. 6A; $17 \pm 5 \%$ rotenone vs. $55 \pm 3 \%$ ALF186+ro- tenone vs. $20 \pm 1 \%$ ODQ+ALF186+rotenone, $\mathrm{p}<0.05)$. Induction of sGG with YG-1 stabilized mitochondrial membrane potential (rotenone $17 \pm 5 \%$ of the mitochondrial membrane potential vs. YC-1+rotenone $33 \pm 6 \%, \mathrm{p}<0.05)$, even though this effect was less pronounced than with ALF186. We next mimicked sGG activation by incubating cells with the cell-permeable cGMPanalogue 8-Br-cGMP. Indeed, 8-Br-cGMP afforded significant protection, which was not as pronounced as that observed with 
A

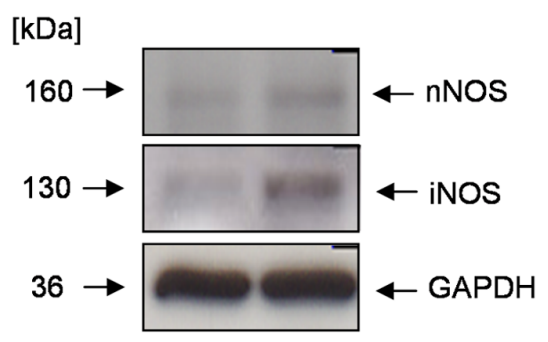

ALF186 $\quad-\quad 50 \mu \mathrm{mol} / \mathrm{L}$

$\mathrm{B}$

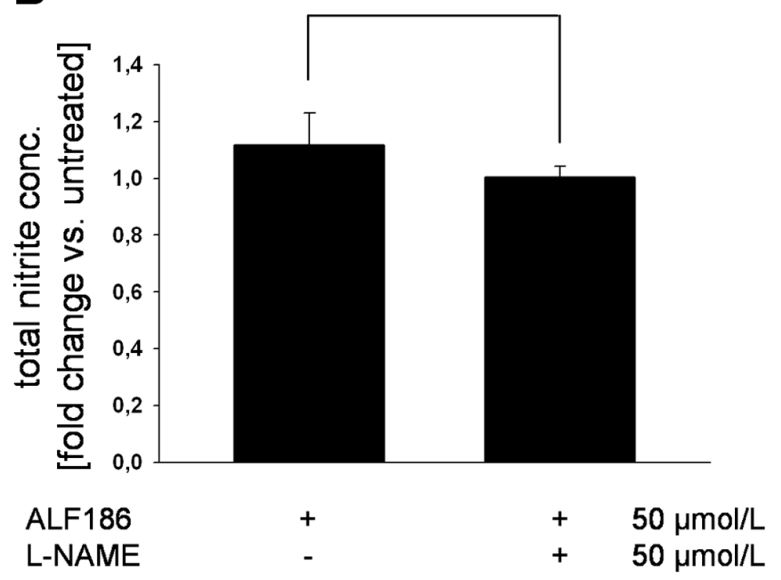

C

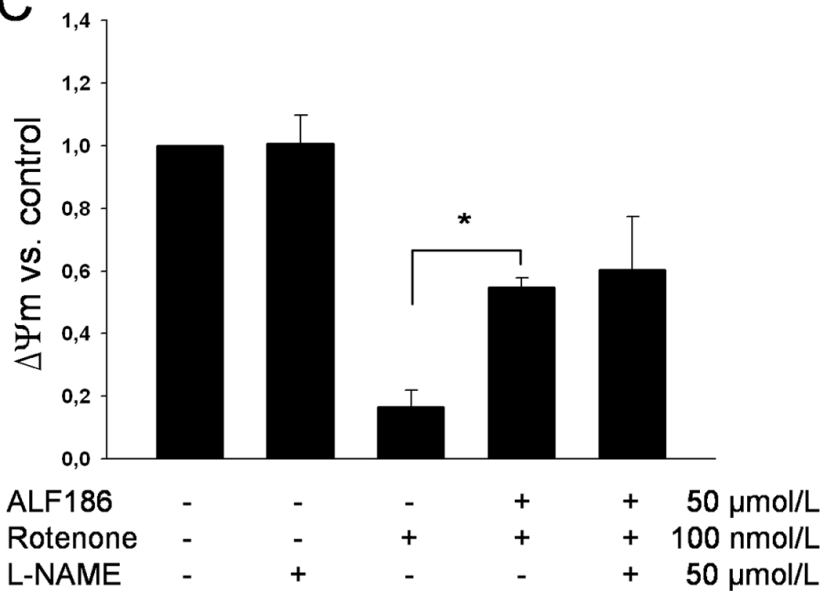

Figure 3. The role of the heme-containing "primary" CO-target NOS in ALF186 mediated effects. A: Representative western blot of nNOS and iNOS protein expression after ALF186 treatment. B: Quantification of nitric oxide production by colorimetric measurement of total nitrite after ALF186 incubation \pm NOS-Inhibition by L-NAME $\left(n=6\right.$; fold change vs. untreated cells; mean \pm SD; ${ }^{*}=p<0.05$ ALF186 vs. L-NAME + ALF186). C: Flow-cytometric analysis of mitochondrial membrane potential change relative to untreated cells after inhibition of NOS $\left(\Delta \Psi_{m}, n=6 ;\right.$ mean $\pm S D$; $*=p<0.05$ rotenone vs. ALF186+rotenone). doi:10.1371/journal.pone.0060672.g003

A

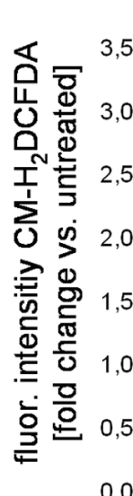

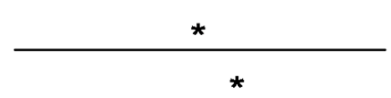
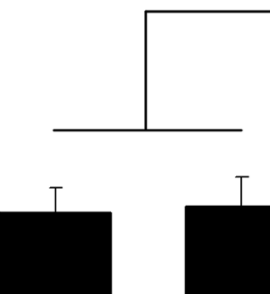

.
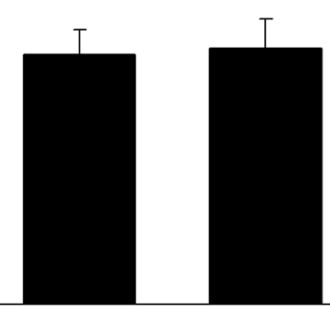

$+$

ALF186

PMA

Rotenone

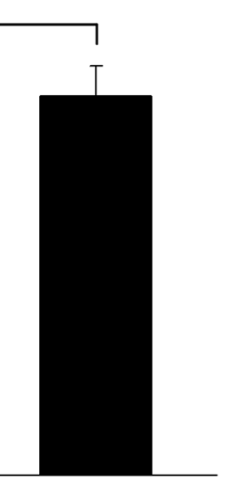

$\begin{array}{rr}- & 50 \mu \mathrm{mol} / \mathrm{L} \\ - & 1 \mu \mathrm{mol} / \mathrm{L} \\ + & 100 \mathrm{nmol} / \mathrm{L}\end{array}$
B

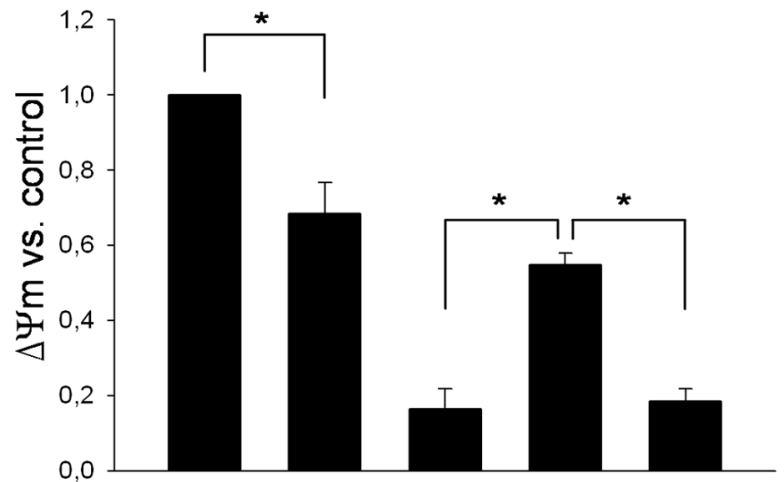

ALF186

ALF186

DPI
$+50 \mu \mathrm{mol} / \mathrm{L}$

$+100 \mathrm{nmol} / \mathrm{L}$

$+10 \mu \mathrm{mol} / \mathrm{L}$

Figure 4. Influence of ALF186 on ROS production and role of NADPH oxidase in ALF186 mediated effects. A: Flow-cytometric analysis of ROS production after CM-H $\mathrm{H}_{2}$ DCFDA staining $\left(n=6\right.$; mean \pm SD; ${ }^{*}=p<0.05$ all vs. untreated; rotenone vs. ALF186 and vs. PMA). B: Flow-cytometric analysis of mitochondrial membrane potential change relative to untreated cells after NADPH oxidase inhibition $\left(\Delta \Psi_{m}, n=6 ; m e a n \pm S D ;{ }^{*}=p<0.05\right.$ DPI vs. untreated; rotenone vs. ALF186+rotenone and ALF186+rotenone vs. DPI+ALF186+rotenone).

doi:10.1371/journal.pone.0060672.g004 
A

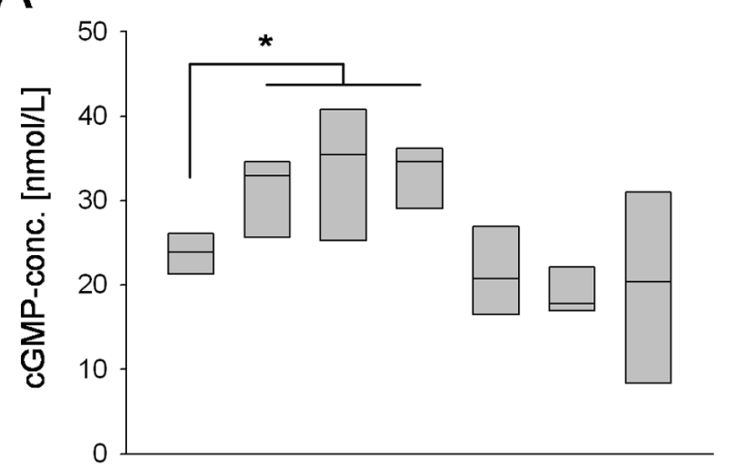

$\begin{array}{llccccccc}\text { ALF186 } & - & 10 & 50 & 100 & - & - & - & \mu \mathrm{mol} / \mathrm{L} \\ \text { iALF186 } & - & - & - & - & 10 & 50 & 100 & \mu \mathrm{mol} / \mathrm{L}\end{array}$
B

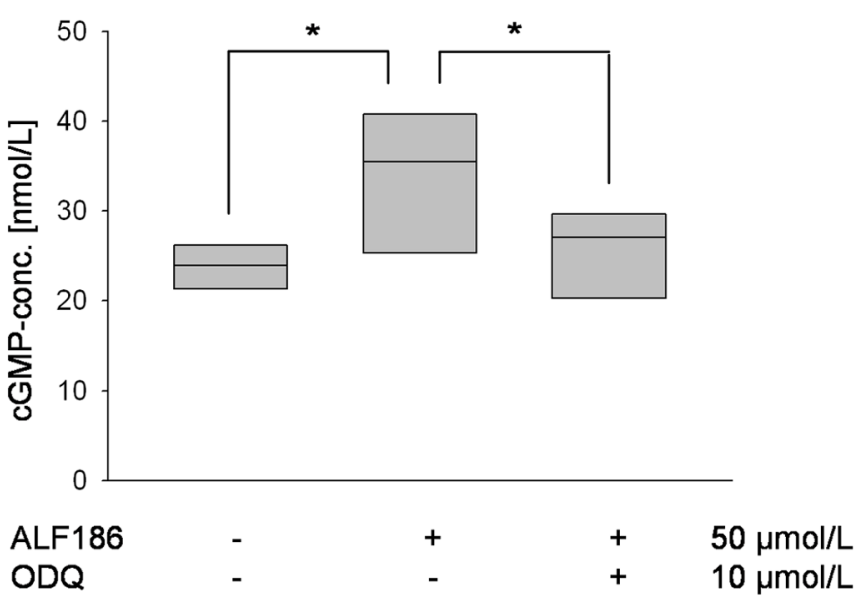

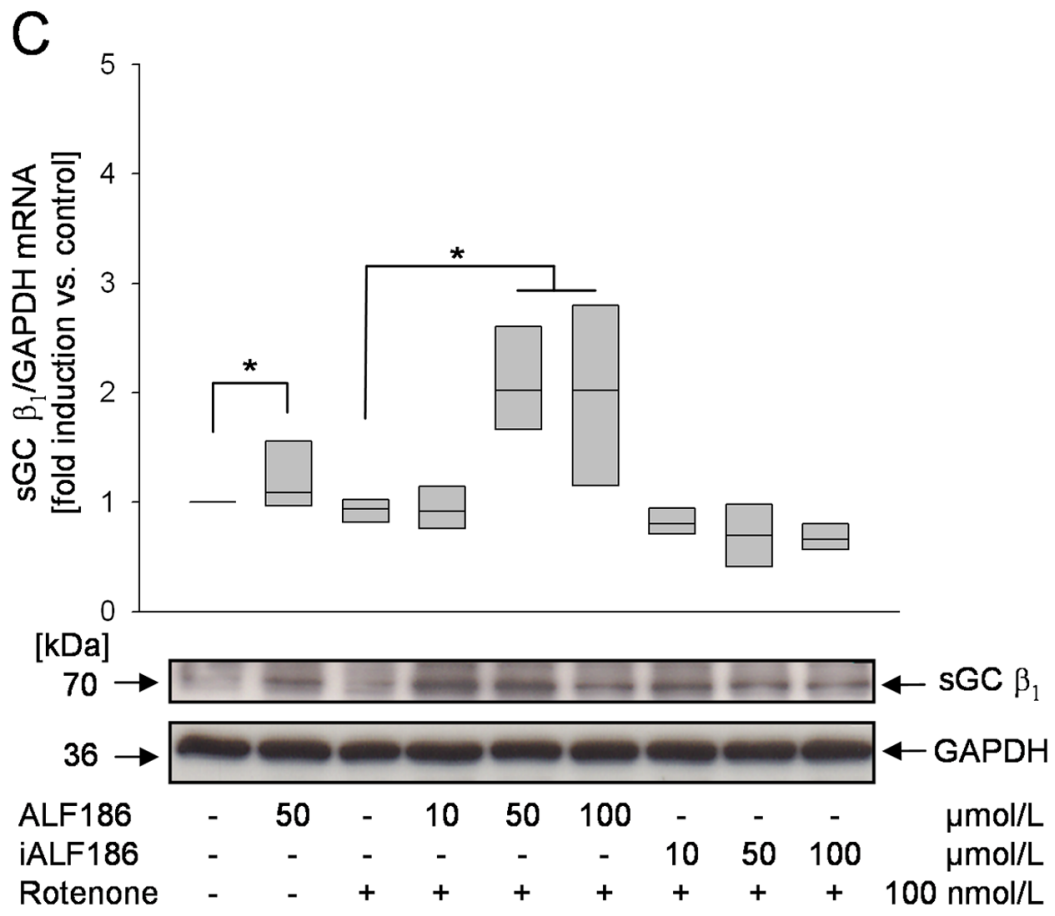

Figure 5. Effect of ALF186 on cellular cGMP levels and expression of sGC. A: ELISA analysis of cellular cGMP concentration after ALF186 treatment $\left(n=6\right.$; median $\pm 25^{\text {th }} / 75^{\text {th }}$ percentile; ${ }^{*}=p<0.05$ untreated vs. ALF186 10, $\left.50,100 \mu \mathrm{mol} / \mathrm{L}\right)$. B: Analysis of cellular cGMP concentration after ALF186 treatment $\pm \mathrm{sGC}$-Inhibition by ODQ $\left(\mathrm{n}=6\right.$; median $\pm 25^{\text {th }} / 75^{\text {th }}$ percentile; ${ }^{*}=\mathrm{p}<0.05$ untreated vs. ALF186 and ALF186 vs. ODQ + ALF186). C: Effect of ALF186 on SGC $\beta_{1}$ subunit mRNA (top; RT-PCR analysis, $\mathrm{n}=6$; median $\pm 25^{\text {th }} / 75^{\text {th }}$ percentile; ${ }^{*}=\mathrm{p}<0.05$ untreated vs. ALF186 $50 \mu \mathrm{mol} / \mathrm{L}$ and rotenone vs. ALF186 50, $100 \mu \mathrm{mol} / \mathrm{L}+$ rotenone) and protein (bottom, representative Western Blot of sGC $\beta_{1}$ protein) expression. doi:10.1371/journal.pone.0060672.g005

ALF186 treatment (Fig. 6B). Several downstream targets are modulated by cGMP, including PKG1. We now asked whether the cGMP-mediated protective effects were dependent on PKG1 activity. PKG1-inhibition with KT5823 abolished ALF186 mediated protection (Fig. 6C).

\section{ALF186 Protects Retinal Ganglion Cells against Ischemia Reperfusion Injury in vivo through $\mathrm{SGC}$}

In a last set of experiments we translated our in vitro results into an in vivo model of neuronal cell damage. Retinal ganglion cells (RGC) are known to be exceptionally susceptible to cell death via apoptosis when subjected to IRI. We therefore used a well- described in vivo model of retinal IRI [3] to investigate potential neuroprotective effects of ALF186 in vivo.

Density-quantification of fluorogold-labeled RGC showed that retinal tissue from animals receiving intravenous ALF186 treatment before injury had significantly higher ganglion cell densities compared to animals treated with vehicle alone $(\mathbf{F i g}$. 7A-7B; IRI $1255 \pm 327 \mathrm{RGC} / \mathrm{mm}^{2}$ vs. ALF186 $10 \mathrm{mg} / \mathrm{kg}+$ IRI $2036 \pm 83$, $\mathrm{p}<0.05)$. RGC densities in corresponding control eyes showed no significant difference from each other $($ Fig. 7A-7B). In vivo cotreatment of animals with the sGC-inhibitor NS-2028 abolished the protective effects mediated by ALF186 Fig. 7A-7B; ALF186 $10 \mathrm{mg} / \mathrm{kg}+\mathrm{IRI} 2036 \pm 83 \mathrm{RGC} / \mathrm{mm}^{2}$ vs. NS-2028 $7 \mathrm{mg} /$ $\mathrm{kg}+\mathrm{ALF} 18610 \mathrm{mg} / \mathrm{kg}+$ IRI $1263 \pm 170, \mathrm{p}<0.05)$. 


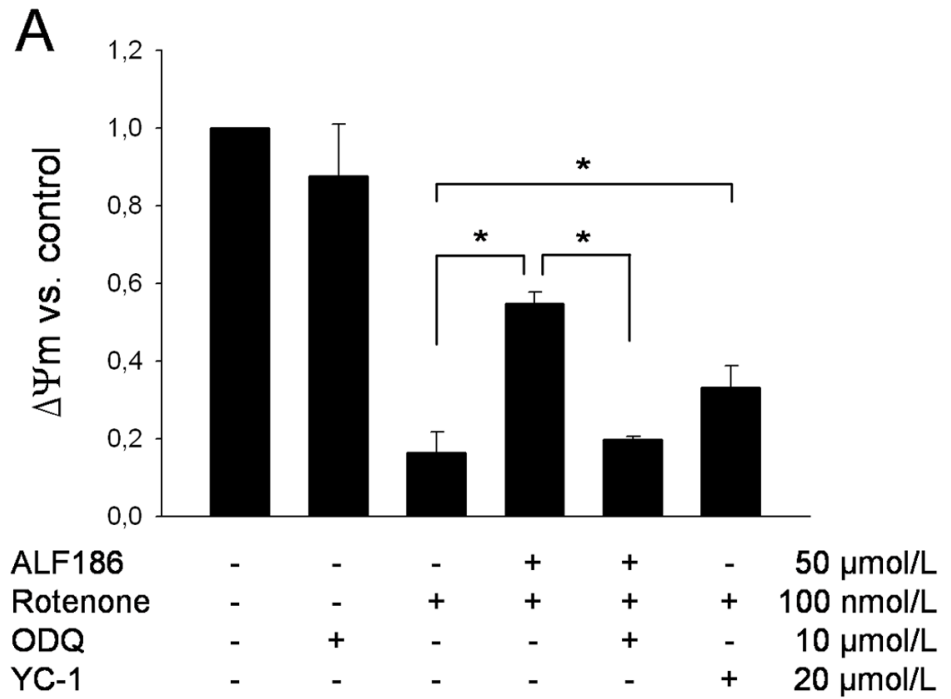

B

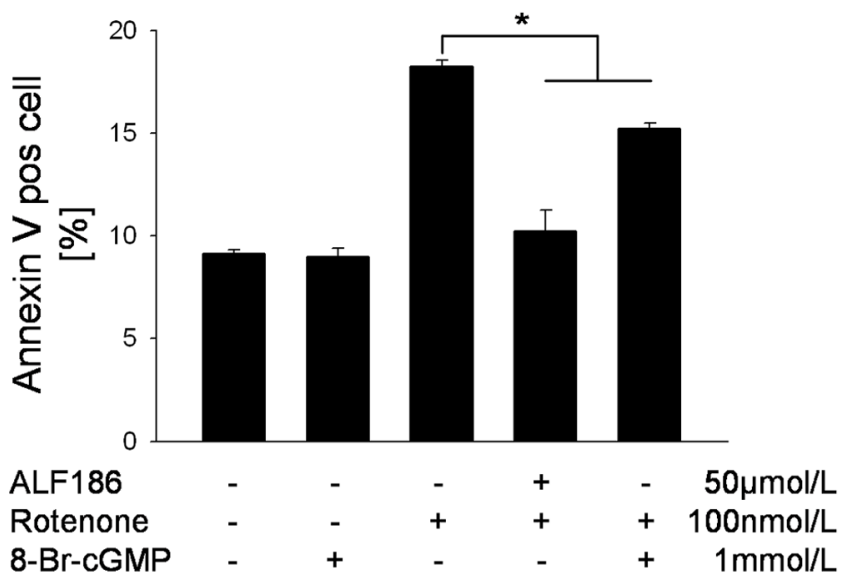

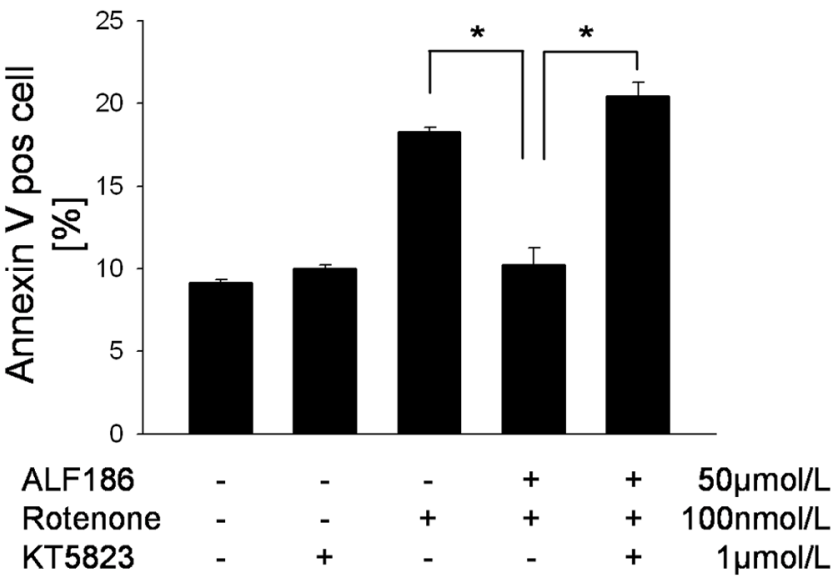

Figure 6. The role of sGC in ALF186 mediated effects. A: Flow-cytometric analysis of mitochondrial membrane potential change relative to untreated cells after inhibition or induction of $\mathrm{sGC}\left(\Delta \Psi_{\mathrm{m}}, \mathrm{n}=6\right.$; mean $\pm \mathrm{SD} ;{ }^{*}=\mathrm{p}<0.05$ rotenone vs. ALF186+ rotenone, ALF186+rotenone vs. $\mathrm{ODQ}+\mathrm{ALF} 186+$ rotenone and rotenone vs. YC-1+rotenone). B: Flow-cytometric analysis after Annexin $\mathrm{V}$ staining and incubation with the cGMP-analog 8-Br-cGMP $\left(n=6 ;\right.$ mean $\pm S D ;{ }^{*}=p<0.05$ rotenone vs. ALF186+rotenone and rotenone vs. 8-Br-cGMP+rotenone). C: Flow-cytometric analysis after Annexin V staining and incubation with the PKG-inhibitor KT5823 $\left(n=6\right.$; mean \pm SD; ${ }^{*}=p<0.05$ rotenone vs. ALF186+rotenone and ALF186+rotenone vs. KT5823+ALF186+rotenone).

doi:10.1371/journal.pone.0060672.g006

To confirm these in vivo results we analyzed the retinal gene expression of pro-apoptotic (Caspase-3, Bax) and anti-apoptotic (Bcl-2) genes using RT-PCR. Expression of Caspase-3 and Bax was significantly suppressed by ALF186 treatment, whereas sGCinhibition abolished this anti-apoptotic effect (Fig. 8A-8B, Bax: ALF186 $10 \mathrm{mg} / \mathrm{kg}+$ IRI $1.1 \pm 0.3$ fold induction vs. NS-2028 $7 \mathrm{mg} / \mathrm{kg}+$ ALF186 $10 \mathrm{mg} / \mathrm{kg}+\mathrm{IRI} 1.8 \pm 0.4, \mathrm{p}<0.05)$. Expression of Bcl-2 was not altered, by any treatment $(\mathbf{F i g} . \mathbf{8 C})$. In contrast to in vitro gene expression analyses of the ${ }_{\mathrm{sGC}}$ subunits $\alpha_{1}$ and $\beta_{1}$ expression (Fig. 8B), in vivo was not altered by ALF186 (Fig. 8D$\mathbf{E})$.

\section{Discussion}

The main findings can be summarized as follows: (1) Pretreatment with CORM ALF186 attenuates rotenone-induced apoptosis in SY5Y neuroblastoma cells. (2) ALF186 preconditioning influences several heme-containing cellular "primary" targets: (a) NO-Synthase, (b) NADPH-oxidase-derived ROS and (c) sGC. (3) ALF186 protects RGC from IRI through inhibition of apoptosis in vivo that likely involves a similar pathway since sGC inhibition abolishes the protective effects. We therefore hypothesized that CO arising from ALF186 mediated a series of interrelated cascades involving a cGMP/NOS/ROS pathway since inhibition of these pathways at least in vitro abolishes the protective effects. Protection against apoptosis required cGMP and ROS generation, but not NOS. We acknowledge that the link between these signaling molecules requires further study, but we can conclude that preconditioning with CORM ALF186 protects neuronal cells in vitro and in vivo from apoptosis and IRI and that these effects were abrogated when we used the inactive, $\mathrm{CO}$-free ALF186. 
A

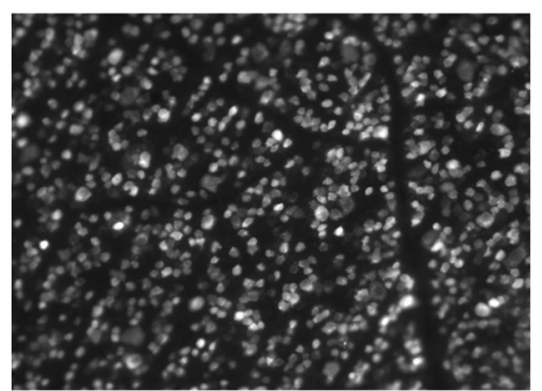

untreated

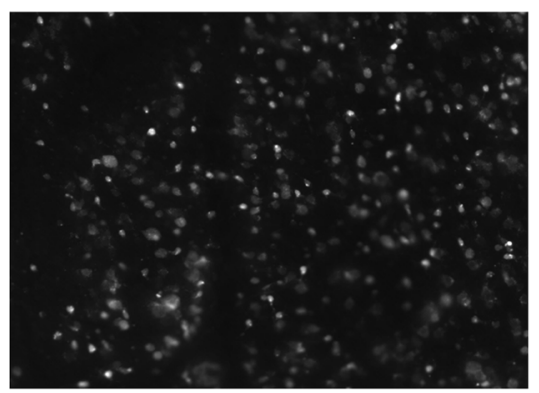

IRI

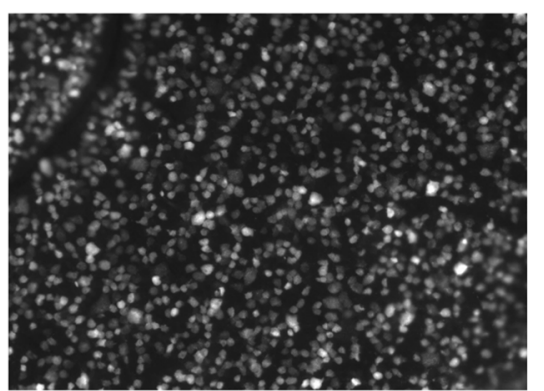

ALF186

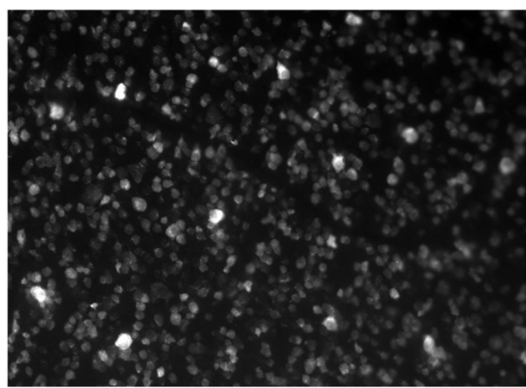

ALF186 + IRI

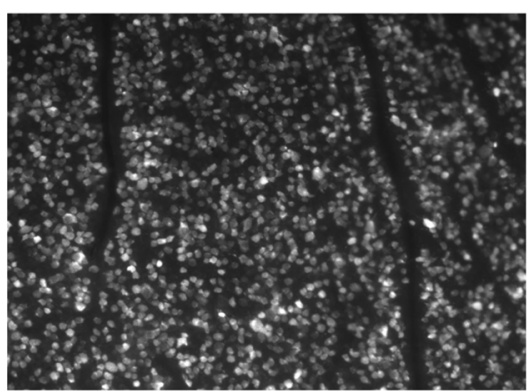

NS-2028 + ALF186

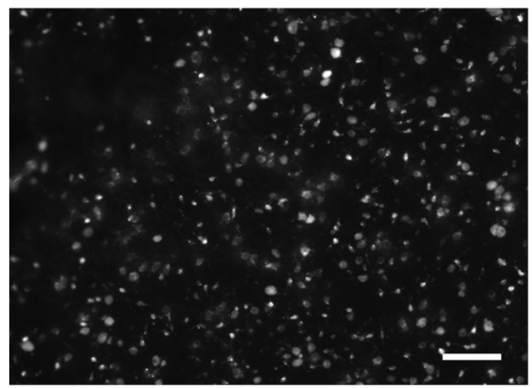

NS-2028 + ALF186 + IRI

B

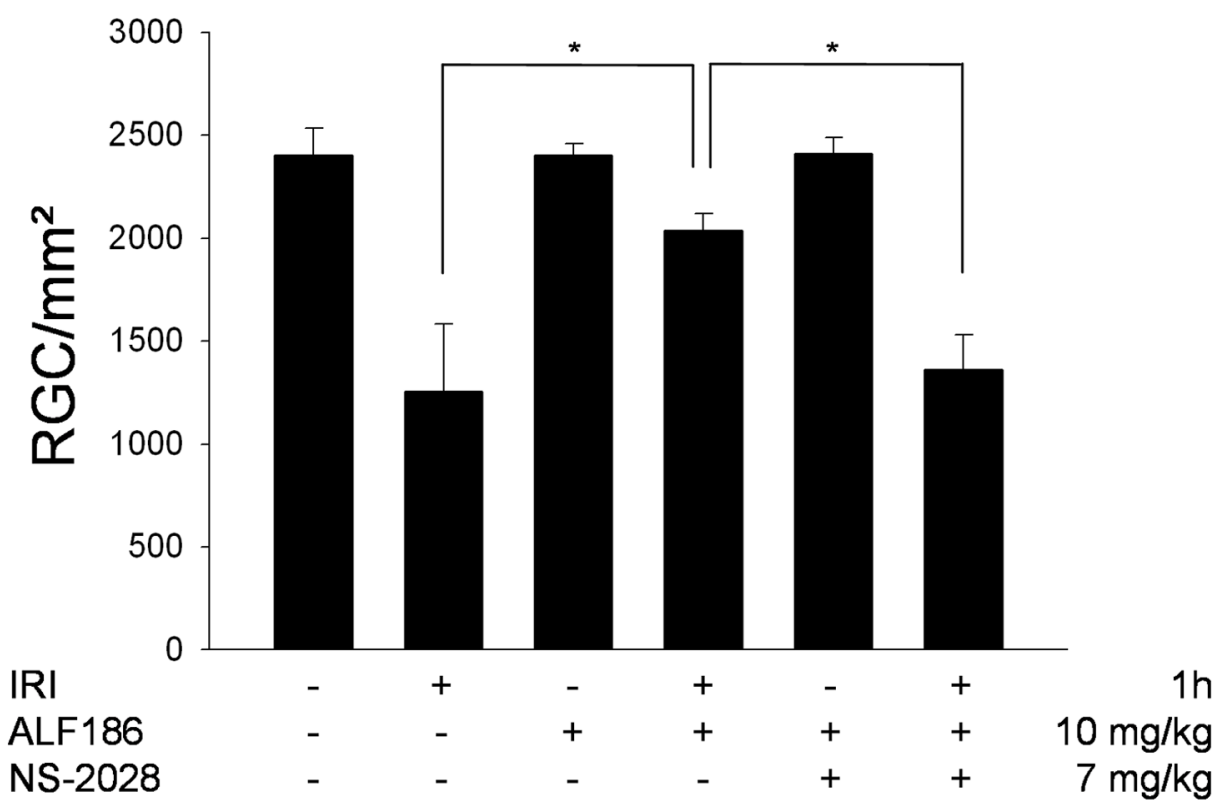

Figure 7. Effect of ALF186 treatment on IRI in retinal ganglion cells in vivo. A: Representative images from flat mounts with fluorogoldlabeled retinal ganglion cells 7 days after IRI, ALF186 treatment and SGC inhibition with NS-2028. Scale bar $100 \mu$ m. B: Quantification of retinal ganglion cell density [cells/mm $\left.{ }^{2}\right] 7$ days after IRI, ALF186 treatment and SGC inhibition in vivo ( $n=6$ per group; mean \pm SD; ${ }^{*}=p<0.05$ IRI vs. ALF186+IRI and ALF186+IRI vs. NS-2028+ALF186+IRI).

doi:10.1371/journal.pone.0060672.g007

Carbon monoxide, a dose-dependent therapeutic gas has profound effects in inhibiting systemic inflammation and apoptosis in numerous in vitro and in vivo models when given either as a preor postconditioning agent resulting in organoprotective actions [10,21-28]. CO can also exert protective effects on neuronal cells in vitro $[2,29]$ and in vivo in small and large animal models $[3,30,31]$. The potential human application of $\mathrm{CO}$ gas is challenging to implement not only for technical reasons, which have been addressed [10], but also for intrinsic flaws including lack of tissue specificity and at present time, hospital-only administration [32]. For these reasons, it is crucial to find alternative routes for the application of CO. CORMs have emerged as an excellent alternative for delivering $\mathrm{CO}$ and have the potential for tissue specificity. ALF186 does not carry such attributes, yet does clearly 

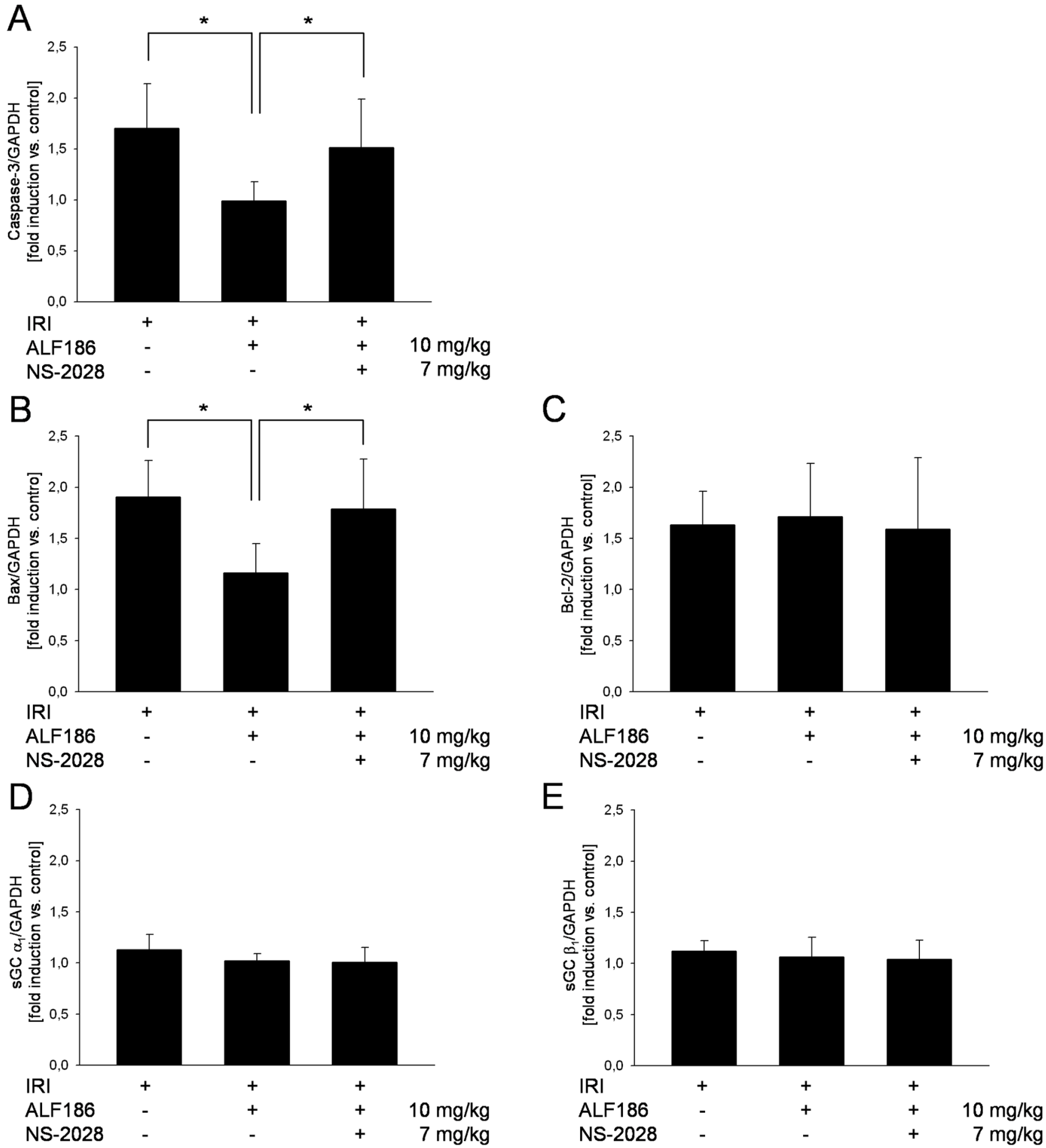

Figure 8. Effect of ALF186 on retinal caspase-3, Bax, Bcl-2 and sGC-subunit gene expression analyzed by RT-PCR. Retinal expression of caspase-3 $\left(\mathbf{A} ; \mathrm{n}=6\right.$; mean \pm SD.; ${ }^{*}=\mathrm{p}<0.05$ IRI vs. ALF186+IRI and ALF186+IRI vs. NS-2028+ALF186+IRI), Bax $\left(\mathbf{B} ; n=6 ; m e a n \pm S D ;{ }^{*}=p<0.05\right.$ IRI vs. ALF186+IRI and ALF186+IRI vs. NS-2028+ALF186+IRI), BCl-2 (C; $n=6$; mean \pm SD), $s G C \alpha_{1}$ subunit $(\mathbf{D} ; n=6 ;$ mean $\pm S D)$ and sGC $\beta_{1}$ subunit $(E ; n=6$; mean \pm SD) mRNA expression in ischemic retinal tissue in relation to the corresponding non-ischemic retinae analyzed by RT-PCR.

doi:10.1371/journal.pone.0060672.g008

demonstrate the feasibility of parenteral delivery. ALF186 is one of a family of CORMs that are orally active leading to similar elevations in $\mathrm{COHb}$ as when given intraperitoneally or intravenously (data not shown) similar to other CORMs [4,13,17,33-39]. Therefore CORMs represent a safe alternative for potential clinical application of $\mathrm{CO}$ [32]. Unlike $\mathrm{CO}$ gas, which has very simple pharmacokinetics, the CORMs carry more complicated pharmacologic challenges that need to be assessed.

To date studies on the effects of CORM-3 on neuronal cells and neuroinflammation have provided inconsistent results [4,5]. With 
the advent of the molybdenum-containing, water-soluble CORMs such as ALF186, GO is released upon contact with oxygen. It has little sensitivity to light and thus features predictable and favorable $\mathrm{CO}$ releasing kinetics with a half life of approximately 15 minutes in aqueous solvents and media in vitro [6] and fast, bolus-like $\mathrm{CO}$ releasing kinetics in vivo [6], the latter of which is likely due to the interaction with hemoglobin.

The in vitro model of rotenone-induced apoptosis in SY5Y neuroblastoma cells is a well-established model of caspasedependent neuronal apoptosis [40,41]. It has been extensively used to study potential neuroprotective effects of endogenous mediators like prostaglandins [42] or chondroitin sulfate [43] and drugs like valproic acid [44], hydrogen sulfide [45], tranexamic acid [46], histamine receptor antagonists [47] or deferoxamine [48]. Consistent with these previous studies, we found increased Annexin V positivity, caspase-3 cleavage and mitochondrial depolarization after rotenone-treatment. Pre-treatment with ALF186 attenuated apoptosis, which was evidenced by decreased Annexin $\mathrm{V}$ positivity, inhibition in caspase-3 cleavage and stabilization of mitochondrial membrane potential all of which were not observed in control experiments with the CO-free inactive ALF186 (iALF186).

Since CO avidly binds to heme groups of cellular structures such as NOS, NADPH oxidase or sGC, it is tempting to assume that the effects of $\mathrm{CO}$ are mediated through alteration of such "primary" CO targets. For example, CORM-2 and CORM-3 exhibit anti-inflammatory effects through reduced $\mathrm{NO}-/$ nitriteproduction and iNOS expression $[11,35,49]$. In contrast to these results, we found that while ALF186 mediated an increase in iNOS and nNOS protein expression in SY5Y cells, it was not involved in protection.

CORM-2 exhibited anti-proliferative effects in smooth muscle cells by blocking NADPH oxidase and the cellular redox system [12]. In contrast, NADPH oxidase derived ROS can promote cell survival through increased endogenous $\mathrm{CO}$ production in endothelial cells [50]. Others have found that $\mathrm{CO}$ gas mediates increased mitochondrial-dependent ROS production in macrophages $[51,52]$. In neuronal SY5Y cells, we also observed an ALF186-mediated increase in ROS production, which we determined to be most likely arising from NADPH oxidase activity as protection was inhibited by DPI, a selective NADPH oxidase inhibitor. Perhaps different modes of CO delivery (gas vs. CORM) can influence the ROS-generating systems of the cell or perhaps speaks to differences in cell types, neurons vs. macrophages.

Vasorelaxing properties of CORM-3, CORM-A1 and ALF186 have been associated with the induction of the hemoprotein sGC

\section{References}

1. Mashour GA, Shanks AM, Kheterpal S (2011) Perioperative stroke and associated mortality after noncardiac, nonneurologic surgery. Anesthesiology 114: 1289-1296.

2. Vieira HL, Queiroga CS, Alves PM (2008) Pre-conditioning induced by carbon monoxide provides neuronal protection against apoptosis. J Neurochem 107: $375-384$.

3. Biermann J, Lagreze WA, Dimitriu C, Stoykow C, Goebel U (2010) Preconditioning with inhalative carbon monoxide protects rat retinal ganglion cells from ischemia/reperfusion injury. Invest Ophthalmol Vis Sci 51: 3784 3791.

4. Bani-Hani MG, Greenstein D, Mann BE, Green CJ, Motterlini R (2006) Modulation of thrombin-induced neuroinflammation in BV-2 microglia by carbon monoxide-releasing molecule 3. J Pharmacol Exp Ther 318: 1315-1322.

5. Yabluchanskiy A, Sawle P, Homer-Vanniasinkam S, Green CJ, Foresti R, et al. (2012) CORM-3, a carbon monoxide-releasing molecule, alters the inflammatory response and reduces brain damage in a rat model of hemorrhagic stroke. Crit Care Med 40: 544-552.

6. Seixas JD, Mukhopadhyay A, Santos-Silva T, Otterbein LE, Gallo DJ, et al. (2012) Characterization of a versatile organometallic pro-drug (CORM) for experimental CO based therapeutics. Dalton Trans 10.1039/c2dt32174b. and a moderate, but significant increase in cGMP production, activation of PKG1 and downstream activation of calciumsensitive potassium channels $[9,13,15,53]$. Moreover, $\mathrm{CO}$ increases retinal and choroidal blood flow in human eyes [54]. However, it is not known whether CORM mediated sGC induction also modulates neuroprotection. sGC is a heterodimer, consisting of an $\alpha$ (1 or 2 ) and heme-containing $\beta$ (1 or 2 ) subunit. Heterodimerization of the enzyme's $\alpha 1$ and $\beta 1$ subunits is essentially necessary for the enzyme's full activity $[55,56]$. There is growing evidence that activation of the sGC-cGMP pathway may also exert cytoprotective and anti-apoptotic effects in neuronal cells [16]. However, no study has investigated possible CORMmediated protective effects in neuronal cells through this pathway. Protective effects by activation of sGC-cGMP signal transduction also seem to be mediated through PKGl activation [16], but little is known about the downstream targets of PKGl that mediate these effects.

The findings of the in vivo study are in accordance with our previous findings in the same experimental model of retinal injury, where administration of inhaled $\mathrm{CO}$ gas before ischemia was antiinflammatory, anti-apoptotic and exerted cytoprotection of RGC [3]. The degree of neuroprotection was comparable between both the application of CO gas and ALF186. We delineate here that ALF186 mediates its neuroprotective effects in vivo through a sGCdependent pathway just as the in vitro experiments have demonstrated. The neuronal cell type and injury model kinetics that we used in vitro and in vivo differed from one another. However, since RGC undergo apoptosis after IRI [57,58] similarly to SH-SY5Y cells do in response to rotenone, both models can be used to assess apoptosis-related neuronal cell death and CO-mediated neuroprotection.

Taken together, this study demonstrates that preconditioning with the novel CORM ALF186 protects neuronal SY5Y and retinal ganglion cells against ischemic insult in part via a sGC dependent pathway. CO released from CORMs may therefore be a treatment option for acute ischemic insults to the retina and the brain by protecting neurons.

\section{Author Contributions}

Conceived and designed the experiments: NS TL UG. Performed the experiments: NS JB UG. Analyzed the data: NS JB UG. Contributed reagents/materials/analysis tools: GR WL LO HB. Wrote the paper: NS CR LO TL UG.

7. Sheikh SZ, Hegazi RA, Kobayashi T, Onyiah JC, Russo SM, et al. (2011) An anti-inflammatory role for carbon monoxide and heme oxygenase-1 in chronic Th2-mediated murine colitis. J Immunol 186: 5506-5513.

8. Rodrigues S, Seixas JD, Guerreiro B, Pereira NMP, Romao CG, et al. (2011) Prevention of Gastric Ulcer by Carbon Monoxide. US 2011/0038955 A1. Feb. 17.

9. Marazioti A, Bucci M, Coletta C, Vellecco V, Baskaran P, et al. (2011) Inhibition of nitric oxide-stimulated vasorelaxation by carbon monoxidereleasing molecules. Arterioscler Thromb Vasc Biol 31: 2570-2576.

10. Motterlini R, Otterbein LE (2010) The therapeutic potential of carbon monoxide. Nat Rev Drug Discov 9: 728-743.

11. Sawle P, Foresti R, Mann BE, Johnson TR, Green CJ, et al. (2005) Carbon monoxide-releasing molecules (CO-RMs) attenuate the inflammatory response elicited by lipopolysaccharide in RAW264.7 murine macrophages. Br J Pharmacol 145: 800-810.

12. Taille C, El-Benna J, Lanone S, Boczkowski J, Motterlini R (2005) Mitochondrial respiratory chain and $\mathrm{NAD}(\mathrm{P}) \mathrm{H}$ oxidase are targets for the antiproliferative effect of carbon monoxide in human airway smooth muscle. J Biol Chem 280: 25350-25360. 
13. Motterlini R, Sawle P, Hammad J, Bains S, Alberto R, et al. (2005) CORM-A1: a new pharmacologically active carbon monoxide-releasing molecule. FASEB J 19: 284-286.

14. Leinders-Zufall T, Shepherd GM, Zufall F (1995) Regulation of cyclic nucleotide-gated channels and membrane excitability in olfactory receptor cells by carbon monoxide. J Neurophysiol 74: 1498-1508.

15. Foresti R, Hammad J, ClarkJE, Johnson TR, Mann BE, et al. (2004) Vasoactive properties of CORM-3, a novel water-soluble carbon monoxide-releasing molecule. Br J Pharmacol 142: 453-460.

16. Fiscus RR (2002) Involvement of cyclic GMP and protein kinase G in the regulation of apoptosis and survival in neural cells. Neurosignals 11: 175-190.

17. Schallner N, Schwemmers S, Schwer CI, Froehlich C, Stoll P, et al. (2011) p38beta-regulated induction of the heat shock response by carbon monoxide releasing molecule CORM-2 mediates cytoprotection in lung cells in vitro. Eur J Pharmacol 670: 58-66.

18. Jehle T, Wingert K, Dimitriu C, Meschede W, Lasseck J, et al. (2008) Quantification of ischemic damage in the rat retina: a comparative study using evoked potentials, electroretinography, and histology. Invest Ophthalmol Vis Sci 49: 1056-1064.

19. Villegas-Perez MP, Vidal-Sanz M, Bray GM, Aguayo AJ (1988) Influences of peripheral nerve grafts on the survival and regrowth of axotomized retinal ganglion cells in adult rats. J Neurosci 8: 265-280.

20. Danias J, Shen F, Goldblum D, Chen B, Ramos-Esteban J, et al. (2002) Cytoarchitecture of the retinal ganglion cells in the rat. Invest Ophthalmol Vis Sci 43: 587-594.

21. Goebel U, Siepe M, Mecklenburg A, Stein P, Roesslein M, et al. (2008) Carbon monoxide inhalation reduces pulmonary inflammatory response during cardiopulmonary bypass in pigs. Anesthesiology 108: 1025-1036.

22. Hoetzel A, Dolinay T, Vallbracht S, Zhang Y, Kim HP, et al. (2008) Carbon monoxide protects against ventilator-induced lung injury via PPAR-gamma and inhibition of Egr-1. Am J Respir Crit Care Med 177: 1223-1232.

23. Otterbein LE, Bach FH, Alam J, Soares M, Tao Lu H, et al. (2000) Carbon monoxide has anti-inflammatory effects involving the mitogen-activated protein kinase pathway. Nat Med 6: 422-428.

24. Otterbein LE, Mantell LL, Choi AM (1999) Carbon monoxide provides protection against hyperoxic lung injury. Am J Physiol 276: L688-694.

25. Otterbein LE, Zuckerbraun BS, Haga M, Liu F, Song R, et al. (2003) Carbon monoxide suppresses arteriosclerotic lesions associated with chronic graft rejection and with balloon injury. Nat Med 9: 183-190.

26. Song R, Kubo M, Morse D, Zhou Z, Zhang X, et al. (2003) Carbon monoxide induces cytoprotection in rat orthotopic lung transplantation via anti-inflammatory and anti-apoptotic effects. Am J Pathol 163: 231-242.

27. Wang X, Wang Y, Kim HP, Nakahira K, Ryter SW, et al. (2007) Carbon monoxide protects against hyperoxia-induced endothelial cell apoptosis by inhibiting reactive oxygen species formation. J Biol Chem 282: 1718-1726.

28. Zhang X, Shan P, Otterbein LE, Alam J, Flavell RA, et al. (2003) Carbon monoxide inhibition of apoptosis during ischemia-reperfusion lung injury is dependent on the p38 mitogen-activated protein kinase pathway and involves caspase 3. J Biol Chem 278: 1248-1258.

29. Almeida AS, Queiroga CS, Sousa MF, Alves PM, Vieira HL (2012) Carbon monoxide modulates apoptosis by reinforcing oxidative metabolism in astrocytes: role of Bcl-2. J Biol Chem 287: 10761-10770.

30. Zeynalov E, Dore S (2009) Low doses of carbon monoxide protect against experimental focal brain ischemia. Neurotox Res 15: 133-137.

31. Mahan VL, Zurakowski D, Otterbein LE, Pigula FA (2012) Inhaled carbon monoxide provides cerebral cytoprotection in pigs. PLoS One 7: e41982.

32. Romao CC, Blattler WA, Seixas JD, Bernardes GJ (2012) Developing drug molecules for therapy with carbon monoxide. Chem Soc Rev 41: 3571-3583.

33. Clark JE, Naughton P, Shurey S, Green CJ, Johnson TR, et al. (2003) Cardioprotective actions by a water-soluble carbon monoxide-releasing molecule. Circ Res 93: e2-8.

34. Urquhart P, Rosignoli G, Cooper D, Motterlini R, Perretti M (2007) Carbon monoxide-releasing molecules modulate leukocyte-endothelial interactions under flow. J Pharmacol Exp Ther 321: 656-662.

35. Megias J, Busserolles J, Alcaraz MJ (2007) The carbon monoxide-releasing molecule CORM-2 inhibits the inflammatory response induced by cytokines in Caco-2 cells. Br J Pharmacol 150: 977-986.

36. De Backer O, Elinck E, Blanckaert B, Leybaert L, Motterlini R, et al. (2009) Water-soluble CO-releasing molecules reduce the development of postoperative ileus via modulation of MAPK/HO-1 signalling and reduction of oxidative stress. Gut 58: 347-356.
37. Vadori M, Seveso M, Besenzon F, Bosio E, Tognato E, et al. (2009) In vitro and in vivo effects of the carbon monoxide-releasing molecule, CORM-3, in the xenogeneic pig-to-primate context. Xenotransplantation 16: 99-114.

38. Tsoyi K, Lee TY, Lee YS, Kim HJ, Seo HG, et al. (2009) Heme-oxygenase-1 induction and carbon monoxide-releasing molecule inhibit lipopolysaccharide (LPS)-induced high-mobility group box 1 release in vitro and improve survival of mice in LPS- and cecal ligation and puncture-induced sepsis model in vivo. Mol Pharmacol 76: 173-182.

39. Tayem Y, Johnson TR, Mann BE, Green CJ, Motterlini R (2006) Protection against cisplatin-induced nephrotoxicity by a carbon monoxide-releasing molecule. Am J Physiol Renal Physiol 290: F789-794.

40. Kitamura Y, Inden M, Miyamura A, Kakimura J, Taniguchi T, et al. (2002) Possible involvement of both mitochondria- and endoplasmic reticulumdependent caspase pathways in rotenone-induced apoptosis in human neuroblastoma SH-SY5Y cells. Neurosci Lett 333: 25-28.

41. Newhouse K, Hsuan SL, Chang SH, Cai B, Wang Y, et al. (2004) Rotenoneinduced apoptosis is mediated by p38 and JNK MAP kinases in human dopaminergic SH-SY5Y cells. Toxicol Sci 79: 137-146.

42. Wang X, Qin ZH, Leng Y, Wang Y, Jin X, et al. (2002) Prostaglandin A1 inhibits rotenone-induced apoptosis in SH-SY5Y cells. J Neurochem 83: 1094 1102.

43. Canas N, Valero T, Villarroya M, Montell E, Verges J, et al. (2007) Chondroitin sulfate protects SH-SY5Y cells from oxidative stress by inducing heme oxygenase-1 via phosphatidylinositol 3-kinase/Akt. J Pharmacol Exp Ther 323: 946-953.

44. Xiong N, Jia M, Chen C, Xiong J, Zhang Z, et al. (2011) Potential autophagy enhancers attenuate rotenone-induced toxicity in SH-SY5Y. Neuroscience 199: 292-302.

45. Hu LF, Lu M, Wu ZY, Wong PT, Bian JS (2009) Hydrogen sulfide inhibits rotenone-induced apoptosis via preservation of mitochondrial function. Mol Pharmacol 75: 27-34.

46. Kim HJ, Park HJ, Park HK, Chung JH (2009) Tranexamic acid protects against rotenone-induced apoptosis in human neuroblastoma SH-SY5Y cells. Toxicology 262: 171-174.

47. Park HJ, Kim HJ, Park HK, Chung JH (2009) Protective effect of histamine H2 receptor antagonist ranitidine against rotenone-induced apoptosis. Neurotoxicology 30: 1114-1119.

48. Wu Y, Li X, Xie W, Jankovic J, Le W, et al. (2010) Neuroprotection of deferoxamine on rotenone-induced injury via accumulation of HIF-1 alpha and induction of autophagy in SH-SY5Y cells. Neurochem Int 57: 198-205.

49. Tsoyi K, Nizamutdinova IT, Jang HJ, Mun L, Kim HJ, et al. (2010) Carbon monoxide from CORM-2 reduces HMGB1 release through regulation of IFNbeta/JAK2/STAT-1/INOS/NO signaling but not COX-2 in TLR-activated macrophages. Shock 34: 608-614.

50. Basuroy S, Tcheranova D, Bhattacharya S, Leffler CW, Parfenova H (2011) Nox4 NADPH oxidase-derived reactive oxygen species, via endogenous carbon monoxide, promote survival of brain endothelial cells during TNF-alphainduced apoptosis. Am J Physiol Cell Physiol 300: C256-265.

51. Zuckerbraun BS, Chin BY, Bilban M, d'Avila JC, Rao J, et al. (2007) Carbon monoxide signals via inhibition of cytochrome $\mathrm{c}$ oxidase and generation of mitochondrial reactive oxygen species. FASEB J 21: 1099-1106.

52. Bilban M, Bach FH, Otterbein SL, Ifedigbo E, d'Avila JC, et al. (2006) Carbon monoxide orchestrates a protective response through PPARgamma. Immunity 24: 601-610.

53. Archer SL, Huang JM, Hampl V, Nelson DP, Shultz PJ, et al. (1994) Nitric oxide and cGMP cause vasorelaxation by activation of a charybdotoxin-sensitive K channel by cGMP-dependent protein kinase. Proc Natl Acad Sci U S A 91: 7583-7587.

54. Resch H, Zawinka C, Weigert G, Schmetterer L, Garhofer G (2005) Inhaled carbon monoxide increases retinal and choroidal blood flow in healthy humans. Invest Ophthalmol Vis Sci 46: 4275-4280.

55. Buechler WA, Nakane M, Murad F (1991) Expression of soluble guanylate cyclase activity requires both enzyme subunits. Biochem Biophys Res Commun 174: $351-357$.

56. Russwurm M, Behrends S, Harteneck C, Koesling D (1998) Functional properties of a naturally occurring isoform of soluble guanylyl cyclase. Biochem J 335 (Pt 1): 125-130.

57. Li SY, Yang D, Yeung CM, Yu WY, Chang RC, et al (2011) Lycium barbarum polysaccharides reduce neuronal damage, blood-retinal barrier disruption and oxidative stress in retinal ischemia/reperfusion injury. PLoS One 6: e16380.

58. Zhang Z, Qin X, Tong N, Zhao X, Gong Y, et al. (2012) Valproic acidmediated neuroprotection in retinal ischemia injury via histone deacetylase inhibition and transcriptional activation. Exp Eye Res 94: 98-108. 